\title{
Effect of Chloramphenicol and Streptomycin on Developmental Stages of Phytophthora infestans
}

\author{
By DIANA M. ROOKE*† AND R. C. SHATTOCK \\ School of Plant Biology, University College of North Wales, Bangor, Gwynedd LL57 2UW, U.K.
}

(Received 31 May 1983)

\begin{abstract}
Chloramphenicol and streptomycin inhibited vegetative growth and sporulation of wild-type isolates of Phytophthora infestans (B.25, C1234, respectively) but not the corresponding resistant isolates $(C r, S r)$, or a streptomycin-dependent mutant $(S d)$; in the latter streptomycin was stimulatory. Chloramphenicol inhibited zoospore release in $B .25$ and $C r$ but direct sporangial germination of $\mathrm{Cr}$ was reduced only at high concentrations. Streptomycin inhibited zoospore release and direct sporangial germination equally in wild-type and $S r$. Chloramphenicol was fungistatic, whereas streptomycin was fungistatic or fungicidal, depending on its concentration and length of incubation with the fungus. Delayed addition of antibiotics to liquid cultures of the wild-type isolates reduced growth inhibition.
\end{abstract}

\section{INTRODUCTION}

Fungi such as Allomyces, Blastocladiella and several Oomycetes are susceptible to the antibacterial antibiotics chloramphenicol (CM) and streptomycin (SM) (Vörös, 1965; Matsumae \& Cantino, 1971; Hendrix, 1974; Burke \& Germond, 1976), although their degree of antibiotic sensitivity appears to be species or strain specific (Muller, 1958; Vaartaja, 1960; Ogawa et al., 1960; Shaw, 1965; Vörös, 1965; Marchant \& Smith, 1968; Griffin \& Coley-Smith, 1971; Ersek et al., 1972; Cohen \& Perl, 1973; Beakes \& Gay, 1980; Leary et al., 1982). These antibiotics are reputedly fungistatic in their action (Vörös, 1963) and their growth inhibitory effects are reversible.

In common with other Oomycetes, growth and sporulation of wild-type isolates of Phytophthora infestans is reduced by CM (Ersek et al., 1972; Shattock \& Shaw, 1975) and by SM (Muller et al., 1954; Vörös, 1963; Swiezynski \& Jankowska, 1970; Cohen \& Perl, 1973; Shattock \& Shaw, 1975). Streptomycin also inhibits differentiation and release of zoospores from sporangia, and their subsequent encystment and germination (Griffin \& Coley-Smith, 1971; Cohen \& Perl, 1973) and has been used experimentally as a fungicide against $P$. infestans and several other species of the Peronosporales (Coley-Smith, 1966; Griffin \& Coley-Smith, 1971; Cohen \& Perl, 1973; Crute et al., 1977).

Within the genus Phytophthora mutant isolates resistant to CM or SM singly are available for investigation (Shaw \& Elliot, 1968; Shaw \& Khaki, 1971; Dyakov \& Vishtynezkaja, 1973; Khaki \& Shaw, 1974; Shattock \& Shaw, 1975; Carnes \& Leary, 1977). This paper extends the initial characterization of antibiotic-resistant mutants obtained in $P$. infestans (Shattock \& Shaw, 1975), with a comparison of the susceptibility of the wild-type and mutant isolates to the antibiotics. Factors influencing antibiotic toxicity during vegetative growth were also investigated.

\section{METHODS}

Organism. Isolates of Phytophthora infestans used were strains $C r$, resistant to $\mathrm{CM}$, derived from wild-type isolate $B .25$; $S r$, resistant to SM, derived from isolate C1234 and $S d$, dependent on SM and isolated from $S r$ (Shattock \& Shaw, 1975).

$\dagger$ Present address: Department of Microbiology, The Medical School, The University, Newcastle upon Tyne NE1 7RU, U.K. 
Media and cultural techniques. The isolates were grown in plastic $9 \mathrm{~cm}$ diameter Petri dishes on rye A or rye B agar (1.5\%, w/v, Oxoid no. 3) (Caten \& Jinks, 1968) or in shaken liquid culture in acid-washed, rinsed conical flasks $(100 \mathrm{ml})$ containing rye $\mathrm{B}$ broth $(20 \mathrm{ml})$ at a standard incubation temperature of $18{ }^{\circ} \mathrm{C}$ in darkness.

Chloramphenicol (Sigma) was dispensed into liquid or cooled, molten agar medium either as the powder or from a sterile aqueous stock solution $\left(2 \mathrm{mg} \mathrm{ml}^{-1}\right.$ ). Streptomycin sulphate (Sigma), theoretical potency $798 \mu \mathrm{gl}^{-1}$, was dispensed from aqueous stock solution of $10 \mathrm{mg} \mathrm{ml}^{-1}$, converted to streptomycin base. Stock solutions were kept in the dark at $4^{\circ} \mathrm{C}$.

Agar media were inoculated centrally with hyphal plugs $(4 \mathrm{~mm})$ cut from the margin of established mycelial cultures. Sporangial suspensions were obtained by flooding an agar culture with sterile distilled water $(5 \mathrm{ml})$ and gentle raking of the surface growth with a wire loop. The suspensions were incubated with vancomycin (Vancocin $\mathrm{HCl}$, Eli Lilly \& Co., U.S.A.) at $200 \mu \mathrm{g} \mathrm{ml}^{-1}$ final concentration for $6 \mathrm{~h}$ to ensure bacteria-free cultures, seeded $(0.2 \mathrm{ml}$ per plate) on to fresh rye A agar and incubated for 5-7 d before harvest to produce sufficient numbers of sporangia for germination experiments. Liquid media were inoculated with hyphal 'wefts' supported on cellophane squares. These were produced on rye $A$ agar by allowing mycelia from a central inoculum (8 $\mathrm{mm})$ to grow over a circle of presterilized cellophane squares $(10 \mathrm{~mm} \times 10 \mathrm{~mm})$ with their innermost edge $7 \mathrm{~mm}$ distant from the inoculum. Isolate $S d$, growing on rye A agar with SM $\left(200 \mu \mathrm{g} \mathrm{ml}^{-1}\right)$ was passaged twice on medium without antibiotic prior to obtaining weft inocula. After incubation for $7 \mathrm{~d}$, each square was separated from the remaining surface growth by cutting around its periphery with a sterile scalpel, washed once in sterile distilled water $(20 \mathrm{ml})$ and inoculated at the rate of one per flask.

Sporulation. Isolates of $P$, infestans were grown on rye B agar supplemented with CM or SM for $10 \mathrm{~d}$ to determine their effects on sporulation. Colony radius was measured in three replicates of each treatment before harvesting the sporangia. The harvesting procedure was repeated three times for each plate to ensure complete collection, and the sporangia centrifuged ( 2000 r.p.m.) and resuspended in distilled water $(0.5 \mathrm{ml})$. Five replicate counts were carried out for each sample using a counting chamber (Improved Neubauer, Hawkesley, U.K.) and average counts expressed as sporangial number per unit colony area.

Sporangial germination. The sporangia from master cultures were harvested into sterile glucose solution $(0 \cdot 1 \%$, $\mathbf{w} / \mathbf{v}$, double strength) and filtered through sterile muslin to remove hyphal fragments. The sporangial density, determined by counting was equalized between related isolates $(B .25, \mathrm{Cr} ; \mathrm{C1234}, \mathrm{Sr})$ with sterile glucose solution (double strength). A minimum density of $10^{4}$ spores $\mathrm{ml}^{-1}$ was necessary for the experiments (Rooke, 1980).

To assess the effects of the antibiotics on zoospore release from sporangia equal volumes $(0.5 \mathrm{ml})$ of sporangial suspension and sterile aqueous solutions of antibiotic were incubated in Pyrex beakers $(25 \mathrm{ml})$ for $6 \mathrm{~h}$ at $12^{\circ} \mathrm{C}$ in darkness. Six drops from each were placed on a microscope slide and fixed in the vapour of Newcomer's solution (Newcomer, 1953). Direct germination of sporangia was monitored using the same procedure, except that after antibiotic addition, six drops per treatment were transferred to a microscope slide and thereafter incubated in a damp chamber at $24^{\circ} \mathrm{C}$ for $24 \mathrm{~h}$ in darkness before fixation. A minimum of 500 sporangia per drop was scored microscopically for germination. Absence of the sporangial papilla was the criterion for zoospore release (Griffin \& Coley-Smith, 1971); microscopically identifiable germ tubes constituted direct germination. At least three replicate experiments were carried out. The data were corrected for natural mortality and the germination in antibiotic treatments expressed as percentages of the controls. The replicate percentage inhibition values were transformed into probit values and the transformed data plotted against the logarithm of the antibiotic concentration with a computer, from which $\mathrm{ED}_{50}$ values of the antibiotics were calculated.

Vegetative growth. Cultures for studies of growth inhibition were set up in liquid medium supplemented with $\mathrm{CM}$ or SM and incubated for $18 \mathrm{~d}$. Mycelia were harvested and dried at $60^{\circ} \mathrm{C}$ for $48 \mathrm{~h}$ before weighing. Data were obtained from two separate experiments with six replicates per treatment.

Determination of the reversibility of antibiotic inhibition of growth was carried out by incubating weft cultures of the wild-type isolates in liquid medium with various concentrations of $\mathrm{CM}$ or $\mathrm{SM}$ in Petri dishes at $18^{\circ} \mathrm{C}$. At various times during the experiment, four replicate wefts were removed and washed in either two changes ( $30 \mathrm{ml})$ sterile distilled water (isolate $B .25$ ) or once in sterile $10 \mathrm{mM}-\mathrm{MnCl}_{2}(15 \mathrm{ml})$ (isolate $\left.C 1234\right)$ to remove excess wallbound SM (Griffin \& Coley-Smith, 1975), followed by two rinses of sterile distilled water. Each weft was transferred to a flask containing sterile antibiotic-free medium, incubated under standard conditions for a further $14 \mathrm{~d}$ and weighed.

To assess the effect of addition of antibiotics to mycelial cultures at intervals during incubation, wild-type isolates were grown in liquid medium under standard conditions. After incubation for 3,6 or $12 \mathrm{~d}$ the amount of growth of each isolate was determined by dry weight measurements from four replicate flasks. In additional sets of four replicate cultures the medium was removed aseptically and replaced with fresh rye $B$ medium containing $\mathrm{CM}\left(0,10,50,100 \mu \mathrm{g} \mathrm{ml}^{-1}\right)$ or $\operatorname{SM}\left(0,10,50 \mu \mathrm{g} \mathrm{ml}^{-1}\right)$. Mycelial growth was evaluated $14 \mathrm{~d}$ after the addition of antibiotic. Four replicate control cultures of each isolate in medium containing appropriate levels of antibiotic were set up at the start of the experiment (time 0 ) and incubated for $14 \mathrm{~d}$ before weighing.

Photomicrographs of mycelial growth were taken with a Dialux Photomicroscope (Leitz, Wetzlar) fitted with an automatic camera (Orthomat). 
RESULTS

\section{Effect of antibiotics on sporulation}

Sporangial production in wild-type isolates of the fungus was inhibited by CM or SM (Table 1). Isolate $B .25$ showed negligible sporulation at $C M$ levels of $200 \mu \mathrm{g} \mathrm{ml}^{-1}$ and above, whereas the resistant isolate $C r$ was generally less inhibited despite variation in the overall response. A concentration of $20 \mu \mathrm{g} \mathrm{SM} \mathrm{ml}^{-1}$ significantly reduced sporulation in the sensitive isolate C1234. Sporangial production of $S r$, the resistant isolate, in the control treatment was lower than the wild-type $C 1234$ but increased when cultured on medium incorporating $20-100 \mu \mathrm{g} \mathrm{SM} \mathrm{ml}^{-1}$, indicating some stimulation by the antibiotic. Isolate $S d$ produced appreciable numbers of sporangia only in the presence of SM at 50 or $100 \mu \mathrm{g} \mathrm{ml}^{-1}$.

\section{Effect of antibiotics on sporangial germination}

Zoospore release from detached sporangia of all isolates in control treatments was rather low (Fig. 1.). The numbers of sporangia of isolates $B .25$ and $C r$ induced to release zoospores (Fig. $1 a$ ) or germinate directly (Fig. $2 a$ ) were progressively reduced with increasing dosage of $\mathbf{C M}$. Sporangia of isolate $B .25$ were approximately ten times more sensitive to the antibiotic during direct germination than zoospore release, as illustrated by the corresponding $\mathrm{ED}_{50}$ values of the antibiotic calculated from these experiments (Table 2). Sporangia of isolate $\mathrm{Cr}$ tolerated much higher CM levels compared with sporangia of isolate B.25 (Fig. $2 a$ and Table 2).

Streptomycin gradually reduced zoospore release by sporangia of the sensitive (C1234) and resistant isolate $(\mathrm{Sr})$ with increase in concentration (Fig. $1 \mathrm{~b}$ ). Direct germination showed a biphasic response with a rapid reduction in germination up to $80 \mu \mathrm{g} \mathrm{ml}^{-1}$ followed by a gradual decline to total suppression at $200 \mu \mathrm{g} \mathrm{ml}^{-1}$ (Fig. 2b). However, the isolates showed little difference in their sensitivity to SM (Table 2).

Both antibiotics produced a similar qualitative response in germinating sporangia. At low levels of antibiotics zoospore release proceeded as in the controls; cleavage of the sporangial cytoplasm usually resulted in liberation of six to eight biflagellate zoospores per sporangium. With increasing doses of antibiotic a greater proportion of sporangia discharged only one or two zoospores about twice normal size $(12-17 \mu \mathrm{m})$, possessing up to ten flagella and often leaving a remainder of undifferentiated cytoplasm within sporangia. At the highest levels of antibiotic, dark, undifferentiated sporangial cytoplasm was either expelled entirely from, or remained contracted within, the sporangia. During direct germination, increasing antibiotic dose reduced the length of the germ tubes, rather than the number produced per sporangium, eventually resulting in complete inhibition of germ tube emergence.

\section{Effect of antibiotics on vegetative growth}

Chloramphenicol and streptomycin produced identical morphological abnormalities of the hyphae in wild-type $B .25$ and $C 1234$ growing on agar medium containing $C M\left(400 \mu \mathrm{g} \mathrm{ml}^{-1}\right)$ or

\section{Table 1. Effect of antibiotics on sporulation of isolates of P. infestans}

The isolates were grown on rye $\mathrm{B}$ agar at $18^{\circ} \mathrm{C}$ for $10 \mathrm{~d}$. The results are shown as means \pm S.E. for three replicates.

$10^{-2} \times$ Mean no. of sporangia per $\mathrm{mm}^{2}$ colony area

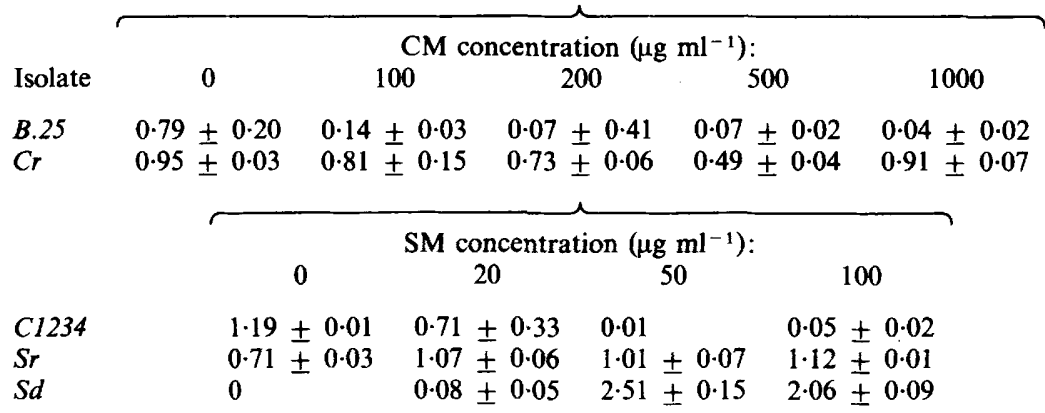




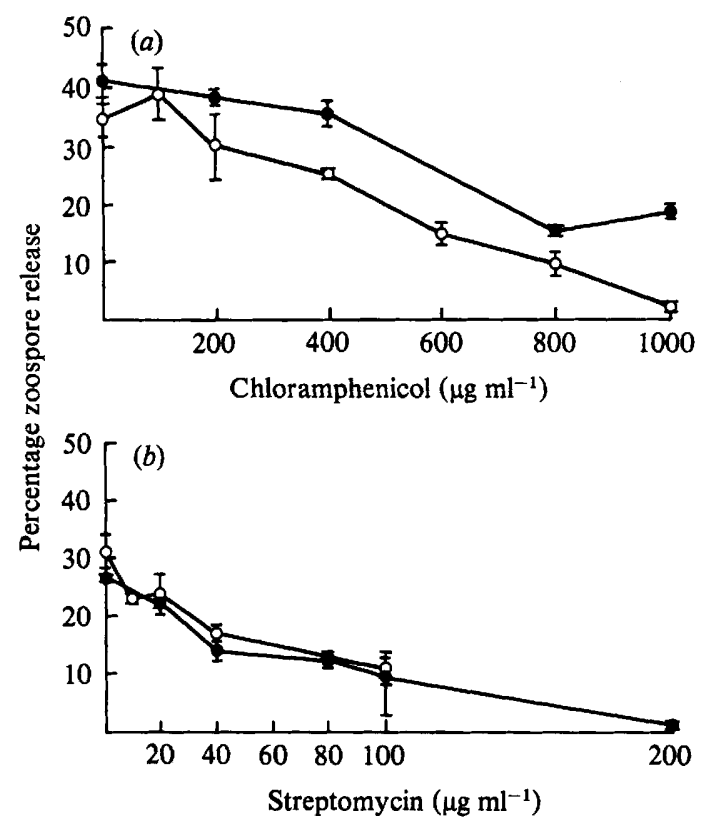

Fig. 1. Effect of antibiotics on release of zoospores from sporangia incubated in $0 \cdot 1 \%$ sterile glucose solution for $6 \mathrm{~h}$ at $12^{\circ} \mathrm{C}$. (a) Isolate $B .25(\mathrm{O})$ and isolate $\mathrm{Cr}(\mathrm{O})$ in the presence of chloramphenicol (results from four experiments); (b) isolate $C 1234(O)$ and isolate $\operatorname{Sr}(O)$ in the presence of streptomycin (results from three experiments). The error bars show the S.E.M.

Table 2. Antibiotic sensitivity of sporangial germination of isolates of $P$. infestans

$\mathrm{ED}_{50}$ values $\left(\mu \mathrm{g} \mathrm{ml}^{-1}\right.$ ) obtained by probit analysis are shown (numbers in parentheses denote the $95 \%$ confidence interval).

\begin{tabular}{|c|c|c|}
\hline \multirow[t]{2}{*}{ Isolate } & Zoospore release & Direct germination \\
\hline & \multicolumn{2}{|c|}{ Chloramphenicol } \\
\hline \multirow{3}{*}{$\begin{array}{l}\text { B. } 25 \\
\mathrm{Cr}\end{array}$} & $527 \cdot 70(471 \cdot 1-599 \cdot 3)$ & $55 \cdot 15(44 \cdot 98-73 \cdot 28)$ \\
\hline & $668 \cdot 70(584 \cdot 9-780 \cdot 3)$ & $367.50(325.4-420.40)$ \\
\hline & \multicolumn{2}{|c|}{ Streptomycin } \\
\hline C1234 & $51.86(43.90-62.14)$ & $35.45(30.77-39.48)$ \\
\hline$S r$ & $44.29(32.82-55.79)$ & $48.45(40 \cdot 38-55 \cdot 24)$ \\
\hline$S d$ & NT & NT \\
\hline
\end{tabular}

SM $\left(100 \mu \mathrm{g} \mathrm{ml}^{-1}\right)$. The branching pattern typical of the control treatment without the antibiotic (Fig. $3 a, b$ ) was replaced by irregular, curling hyphae (Fig. 3c,e). The hyphal apices were often vacuolated and contained regions of granular cytoplasm. Resistant isolates $\mathrm{Cr}$ or $\mathrm{Sr}$ appeared morphologically normal at similar levels (Fig. $3 d, f$ ) and showed corresponding abnormalities only with higher concentrations. Isolate $S d$ responded similarly when deprived of SM but typical morphology was restored in the presence of SM, just as antibiotic-treated susceptible isolates reverted to their normal appearance upon transfer to unsupplemented medium.

In liquid cultures, isolate $\mathrm{Cr}$ continued to grow at levels of $\mathrm{CM}$ sufficient to prevent growth of the sensitive isolate (Fig. 4a). Streptomycin was extremely toxic to isolate C1234 (Fig. $4 b$ ). In contrast, isolate $S r$ tolerated SM but growth started to decline rapidly beyond $40 \mu \mathrm{g} \mathrm{ml}^{-1}$ (Fig. $4 b$ ). Streptomycin was unnecessary for growth of isolate $S d$ in liquid culture but growth was stimulated by $\mathrm{SM}$, reaching a maximum at $10 \mu \mathrm{g} \mathrm{ml}^{-1}$ (Fig. $4 b$ ). 


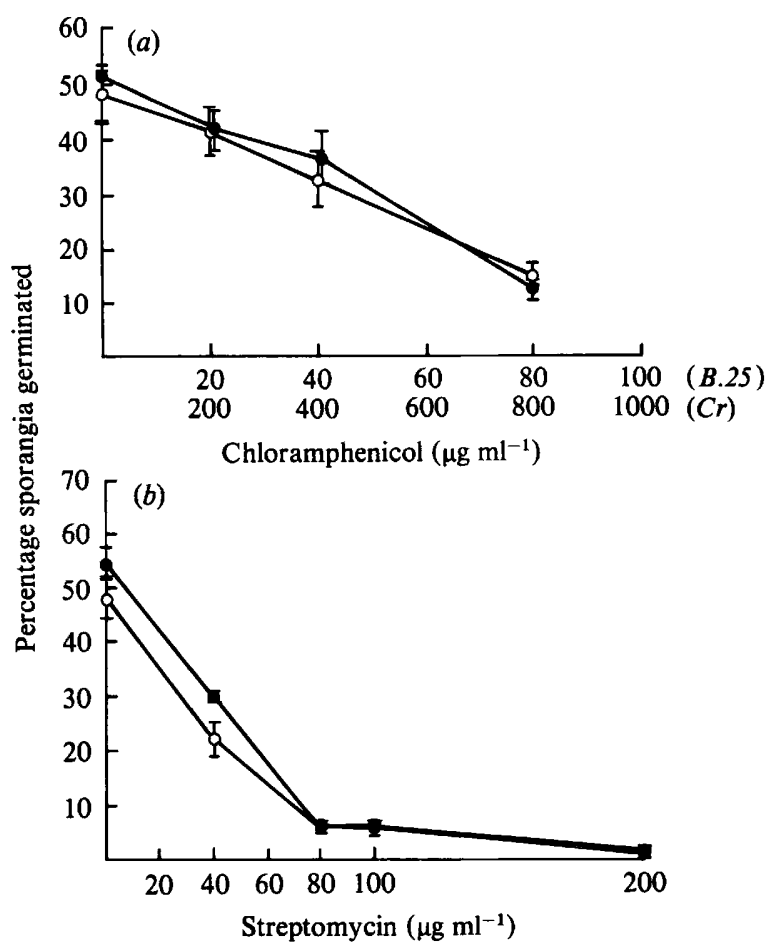

Fig. 2. Effect of antibiotics on direct germination of sporangia incubated in $\mathbf{0 . 1 \%}$ sterile glucose solution for $24 \mathrm{~h}$ at $24^{\circ} \mathrm{C}$. (a) Isolate $B .25(\mathrm{O})$ and isolate $\mathrm{Cr}(\mathrm{O})$ in the presence of chloramphenicol (results from three experiments); (b) isolate $C 1234(\mathrm{O})$ and isolate $S r(O)$ in the presence of streptomycin (results from three experiments). The error bars show the S.E.M.

\section{Reversibility of growth inhibition}

Comparison of the final yields of mycelium of chloramphenicol treatments and control treatments of isolate $B .25$ illustrated the complete reversibility of growth inhibition produced by CM (Fig. 5) irrespective of CM concentration and period of exposure. However recovery of growth of isolate $C 1234$ after SM pretreatment depended on the concentration of SM and its duration of contact with the fungus. Exposure to a relatively low amount of antibiotic $\left(4 \mu \mathrm{g} \mathrm{ml}^{-1}\right)$ beyond $24 \mathrm{~h}$ resulted in diminished recovery (Fig. 5), approaching $85 \%$ inhibition up to $96 \mathrm{~h}$ exposure. The recovery of growth was reduced at higher streptomycin dose and also over shorter time intervals.

\section{Delayed addition of antibiotics}

The consequence of timed addition of the antibiotics on their growth inhibition of sensitive isolates is presented in Fig. 6. Analysis of variance of the data showed that concentration (CM, $P>0.001 ;$ SM, $P>0.001)$ and time (CM, $P>0.001 ; \mathrm{SM}, P>0.05)$ variables were significant for both antibiotic treatments. With the exception of $C M$ at $10 \mu \mathrm{g} \mathrm{ml}^{-1}$ which was contrary to overall trends, the $50,100 \mu \mathrm{g} \mathrm{ml}^{-1}$ additions of the antibiotic inhibited growth of isolate $B .25$ if applied up to a $6 \mathrm{~d}$ preincubation period. However CM was almost totally ineffective when added after $12 \mathrm{~d}$.

Similarly, the growth of isolate $C 1234$ was limited by the presence of $\operatorname{SM}\left(10,50 \mu \mathrm{g} \mathrm{ml}^{-1}\right)$ at the time of inoculation but extension of the pre-incubation period before SM addition appeared to limit its fungitoxicity (Fig. 6). In this case the mycelial growth of cultures to which SM was added after 6 or $12 \mathrm{~d}$ showed a significant increase compared to that after the $3 \mathrm{~d}$ treatment. 

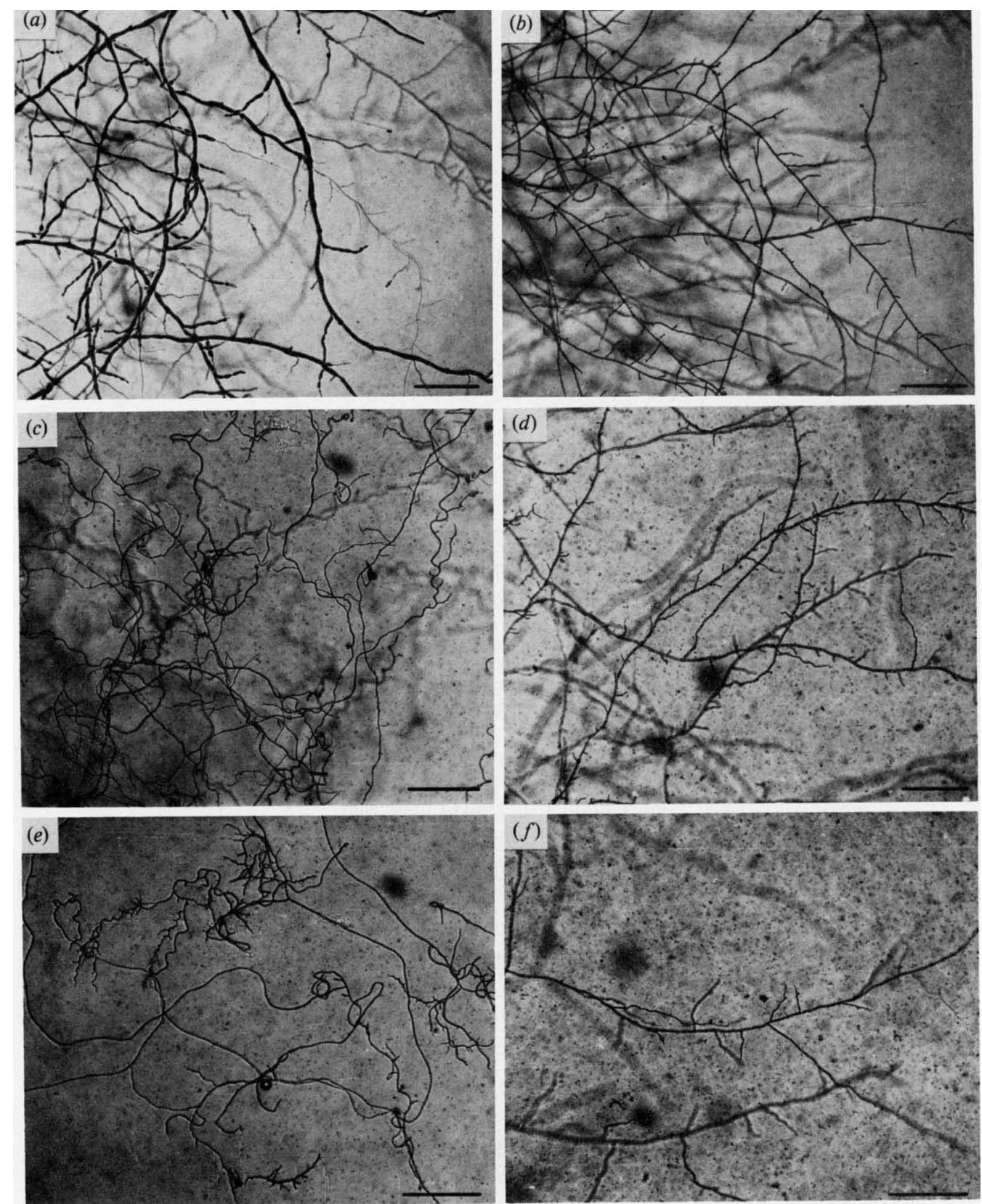

Fig. 3. Morphology of isolates of $\boldsymbol{P}$. infestans grown on rye $\mathbf{B}$ agar with or without chloramphenicol $\left(400 \mu \mathrm{g} \mathrm{ml}^{-1}\right)$ or streptomycin $\left(100 \mu \mathrm{g} \mathrm{ml}^{-1}\right)$ at $18^{\circ} \mathrm{C}$ for $5 \mathrm{~d}$. The bar markers indicate $100 \mu \mathrm{m}$ in $(a)$, $(b),(d)$ and $(f)$ and $500 \mu \mathrm{m}$ in $(c)$ and $(e)$. (a) Isolate B.25, no chloramphenicol; $(b)$ isolate C1234, no streptomycin illustrating typical branching pattern of all isolates in young hyphae near colony margin; (c) isolate $B .25$ with chloramphenicol; $(d)$ isolate $C r$ with chloramphenicol; $(e)$ isolate $C 1234$ with streptomycin; $(f)$ isolate $S r$ with streptomycin. 


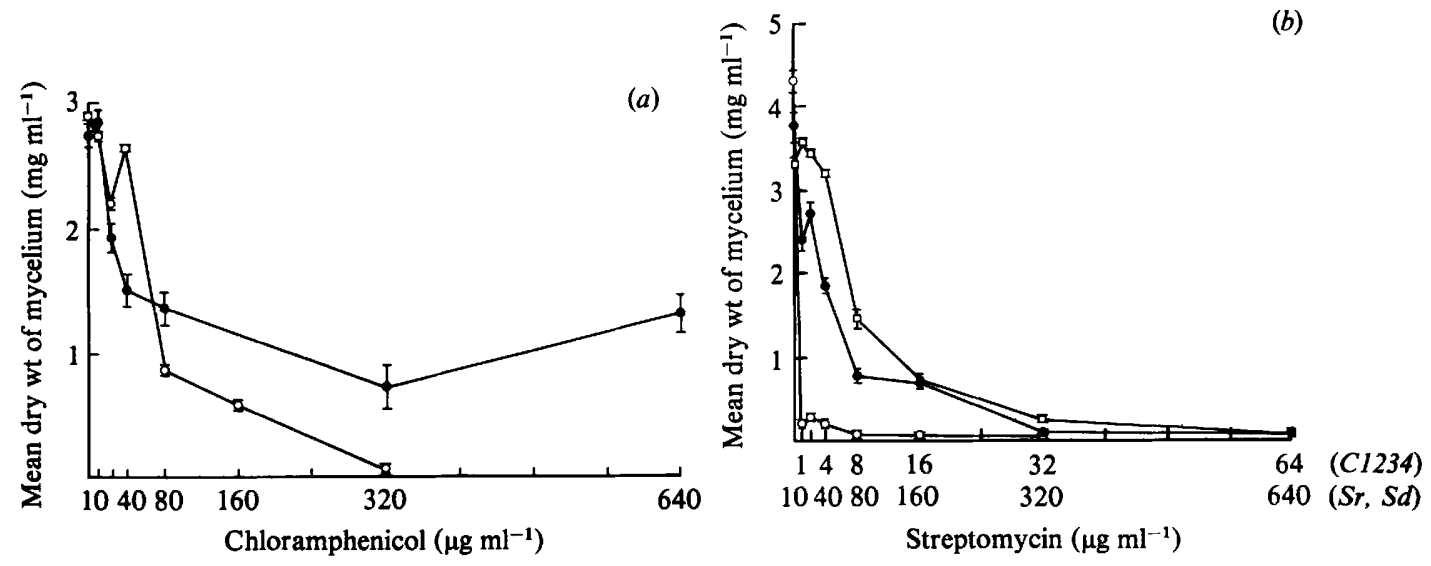

Fig. 4. Effect of antibiotics on vegetative growth of isolates of $P$. infestans incubated in rye $B$ broth for $18 \mathrm{~d}$ at $18^{\circ} \mathrm{C}$. The data are from two experiments. (a) Isolate $B .25(\mathrm{O})$ and $\mathrm{Cr}(\mathrm{O})$ treated with chloramphenicol. (b) Isolate $C 1234(O), S r(O)$ and $S d(\square)$ treated with streptomycin. The error bars show the S.E.M.

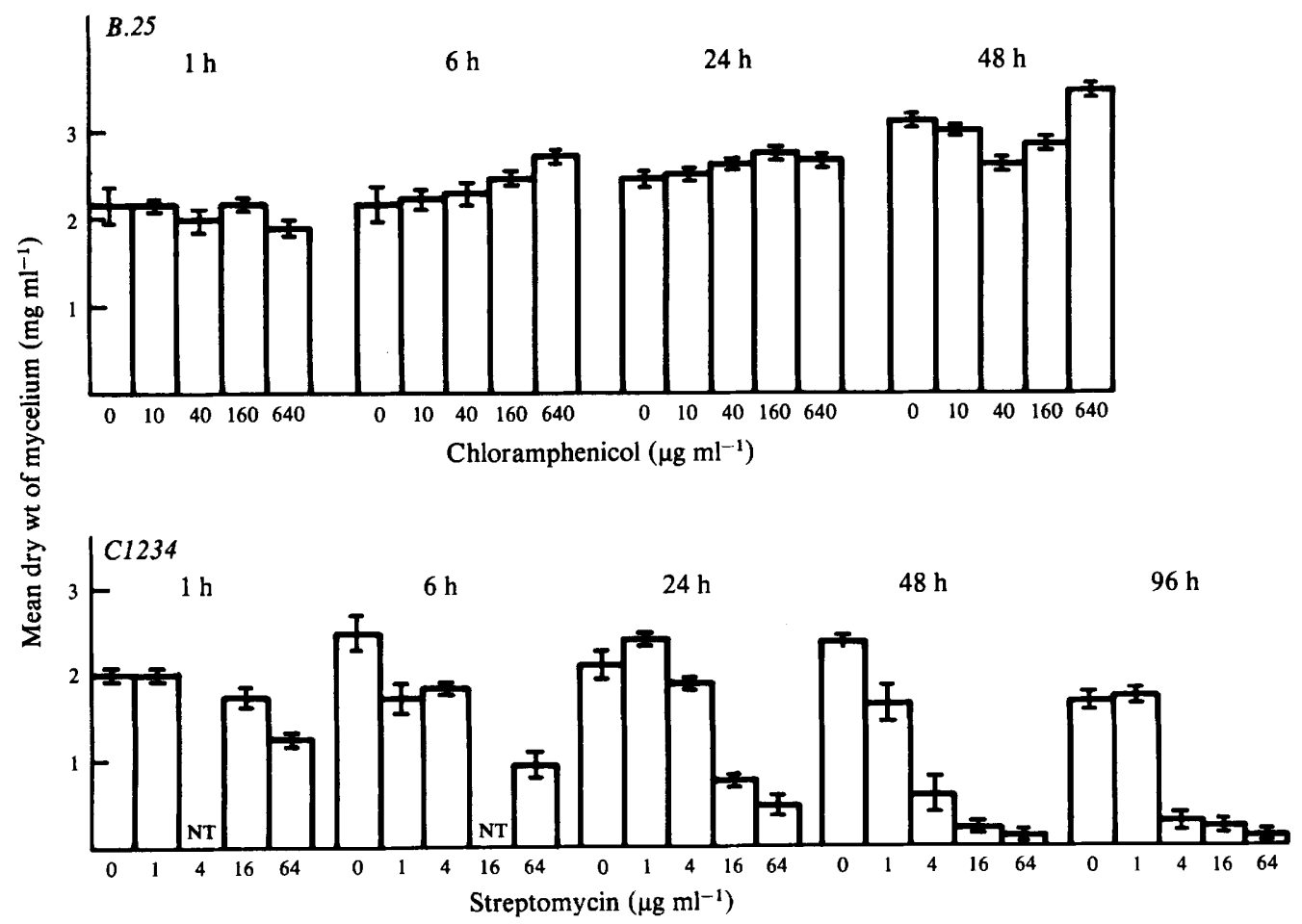

Fig. 5. Mycelial growth of isolates B.25 and C1234 after $14 \mathrm{~d}$ incubation at $18{ }^{\circ} \mathrm{C}$ in antibiotic-free medium, following incubation for $1,6,24,48 \mathrm{~h}$ with various concentrations of antibiotic. NT indicates not tested. The error bars show the S.E.M. 


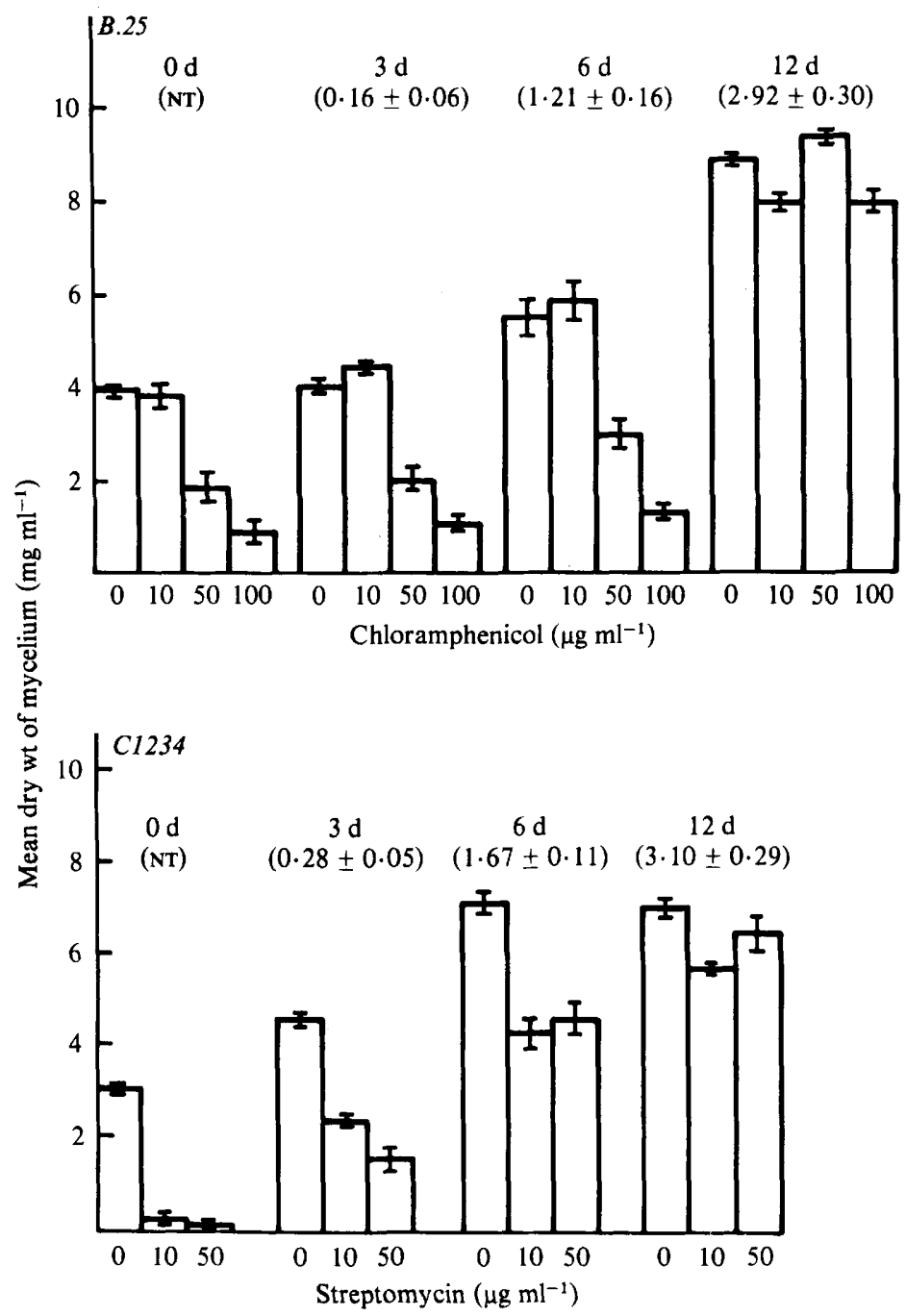

Fig. 6. Mycelial growth of isolates B.25 and $C 1234$ in liquid medium at $18{ }^{\circ} \mathrm{C}$ for $14 \mathrm{~d}$ after addition of $\mathrm{CM}$ or $\mathrm{SM}$, respectively, at $0,3,6,12 \mathrm{~d}$. The values in parentheses represent mean dry weight of mycelium at the time of addition of antibiotic. NT indicates not tested. The error bars show the S.E.M.

\section{DISCUSSION}

Wild-type and resistant isolates of $P$. infestans varied in antibiotic sensitivity at different stages of their life cycle. Resistance or dependence of isolates was most clearly distinguishable during hyphal growth and sporulation of isolates grown with antibiotics. Both streptomycin and chloramphenicol induced marked alteration of hyphal morphology in sensitive isolates, in contrast to streptomycin-treated Saprolegnia (Beakes \& Gay, 1980). Apparently, vegetative growth of all isolates was the most sensitive phase of development tested, conflicting with opinion that mycelial growth is usually the least susceptible to inhibitors (Burke \& Germond, 1976). The percentage zoospore release by all isolates in the absence of antibiotic was relatively low compared with other reports (Uppal, 1926; Griffin \& Coley-Smith, 1971) which may result from attenuation of the isolates in culture. Direct germination of sporangia was more sensitive to antibiotic treatment than zoospore release in wild-type isolates and may reflect dissimilarity of their underlying metabolism; compartmentation of existing material, as occurs in zoospore release being less influenced than the de novo synthesis associated with direct 
germination. In common with the effects of SM in Pseudoperonospora and other isolates of $P$. infestans (Griffin \& Coley-Smith, 1971; Cohen \& Perl, 1973), both antibiotics inhibited cleavage of sporangial cytoplasm during indirect germination but the production of large zoospores probably implies interference with differentiation at a later stage than reported for Saprolegnia (Beakes \& Gay, 1980).

The sensitivity of these isolates in this study differed from previous estimates. Direct sporangial germination in isolate $\mathrm{Sr}$ was more sensitive to $\mathrm{SM}$ than described initially (Shattock \& Shaw, 1975). Chloramphenicol sensitivity of mycelial growth of isolate $B .25$ was greater than reports for other isolates of $P$. infestans (Ersek et al., 1972) and Pythium ultimum (Marchant \& Smith, 1968) although there was no ready explanation for the apparent reduction in vigour of isolate $C r$ in the control situation (Fig. $4 a$ ) compared with the data of Shattock \& Shaw (1975). Similarly SM sensitivity was in general greater, compared with a previous study of these isolates (Shattock \& Shaw, 1975) and of Saprolegnia (Beakes \& Gay, 1980). Such anomalies may reside in properties of the fungus or influences of cultural conditions on the biological activity of the antibiotics. Intraspecific variability is well-documented in $P$. infestans (Caten \& Jinks, 1968; Caten, 1971). Alternatively, variation in the availability of suitable molecular binding sites may determine differences in SM sensitivity at species and developmental levels (Beakes \& Gay, 1980).

In certain cases, differences in apparent toxicity may be due to discrepancies between culture media. Thus, the extent of inhibition of sporulation of isolates resembled that observed on rye A agar (Shattock \& Shaw, 1975) but was greater than on potato tubers (Muller et al., 1954). Instances of increased sensitivity of sporangial germination and mycelial growth of isolates to SM in this study may be a function of the divalent cation conditions, since other assessments of sensitivity have been made in the presence of agar (Shattock \& Shaw, 1975). This contains significant levels of divalent cations (Rooke \& Shattock, 1984) known to antagonize SM toxicity in fungi (McMeekin, 1973; Griffin \& Coley-Smith, 1975). However Cohen \& Perl (1973) reported less inhibition of zoospore release from sporangia of $P$. infestans exposed to SM in distilled water. In the case of mycelial growth it is possible that the modified hyphal weft inoculum, replacing the agar plug inoculum of Shattock \& Shaw (1975), reduced the level of antagonistic cations.

Antibiotic activity may also depend on the concentration, time of dosage and duration of contact with the fungus. Chloramphenicol has been demonstrated to be fungistatic and its growth inhibitory effects are fully reversible, as also occurs in bacteria (Pestka, 1975). The description of SM as fungistatic (Vörös, 1963) was supported only in a situation in which the fungus was exposed either to low levels of SM or for restricted time periods, as with the action of dihydrostreptomycin in bacteria (Kogut et al., 1965). At increased levels SM was rapidly fungicidal in isolate $\mathrm{C} 1234$ and exposure for $1 \mathrm{~h}$ resulted in inhibition of subsequent growth recovery. This may suggest a progressive metabolic derangement at high SM levels or over long exposures which limits recovery. Possibly, rapid accumulation of SM in the fungus allows continued inhibition after removal of external antibiotic. Alternatively sufficient SM remains surface bound after washing to restrict further growth, particularly as washing with $\mathbf{M n C l}_{2}$ was no better than distilled water (Rooke \& Shattock, 1984).

Delaying addition of the antibiotics to growing cultures resulted in a reduction of growth inhibition. The results obtained for SM treatment were similar to those of Cohen \& Perl (1973). Pre-incubation may have several consequences for antibiotic action. The physiological heterogeneity and established metabolism of growing cultures may reduce their susceptibility to antibiotic treatment, compared with fresh inocula. In established cultures SM, which binds to the cell wall before traversing the plasma membrane in bacteria (Shaila \& Gopinath, 1974) and fungi (Griffin \& Coley-Smith, 1975) may be sequestered from the environment by binding to the walls of senescent hyphae. Alternatively, the antibiotics may be inactivated by fungal waste metabolites accumulating during the incubation with fresh medium and antibiotic.

We should like to thank Mr A. Heath for carrying out the probit analyses. This work was carried out under the tenure of an SERC Research Studentship by D.M.R. 


\section{REFERENCES}

Beakes, G. W. \& GAY, J. L. (1980). Effects of streptomycin on the growth and sporulation of Saprolegnia spp. Journal of General Microbiology 119, 361-371.

BurKe, D. D. \& Germond, D. M. (1976). Effect of inhibitors on morphology and growth of Allomyces macrogynus. Journal of General Microbiology 95, 213219.

Carnes, D. W. \& Leary, J. V. (1977). The sensitivity of Phytophthora palmivora to chloramphenicol. Proceedings of the American Phytopathological Society 4, 94-95.

CATEN, C. E. (1971). Single zoospore variation in Phytophthora infestans and attenuation of strains in culture. Transactions of the British Mycological Society 56, 1-7.

Caten, C. E. \& Jinks, J. L. (1968). Spontaneous variability of single isolates of Phytophthora infestans. I. Cultural variation. Canadian Journal of Botany 46, 239-248.

COHEN, Y. \& PERL, M. (1973). stage specificity in streptomycin action against some plant pathogenic Peronosporales. Phytopathology 63, 1172-1180.

Coley-Smith, J. R. (1966). Early season control of hop downy mildew, Pseudoperonospora humuli (Miy. \& Tak.) Wilson, with streptomycin and protectant fungicides in severely infected plantings. Annals of Applied Biology 57, 183-191.

Crute, I. R., Wolfman, S. A. \& Davis, A. A. (1977). A laboratory method of screening fungicides for systemic activity against Bremia lactucae. Annals of Applied Biology 85, 147-152.

Dyakov, Y. T. \& VishtynezKaJA, T. A. (1973). Mutants in Phytophthora infestans (Mont.) de Bary resistant to medicinal substances. Vestnik Moskovskogo universiteta $(V I)$ 28, 57-60 (In Russian, English summary).

ERSEK, T., BARNA, B. \& KIRALY, Z. (1972). Inhibition of Phytophthora infestans by chloramphenicol in vitro and in vivo. Növenytermelés 21, 215 (abstract).

Griffin, M. J. \& Coley-Smith, J. R. (1971). Some effects of streptomycin on Pseudoperonospora humuli, the downy mildew of Hop. Journal of General Microbiology 69, 117-134.

GriffiN, M. J. \& Coley-SmITH, J. R. (1975). Uptake of streptomycin by sporangia of Pseudoperonospora humuli and the inhibition of uptake by divalent cations. Transactions of the British Mycological Society 65, 265-278.

HENDRIX, J. W. (1974). Physiology and biochemistry of growth and reproduction in Pythium. Proceedings of the American Phytopathological Society 1, 207-210.

KhaKI, I. A. \& SHAw, D. S. (1974). The inheritance of drug resistance and compatibility type in Phytophthora drechsleri. Genetical Research 23, 75-86.

Kogut, M., Lightbrown, J. W. \& IsAacson, P. (1965). Effects of dihydrostreptomycin treatment on growth of Escherichia coli after removal of extracellular antibiotic. Journal of General Microbiology 39, $165-183$.

Leary, J. V., Zentmyer, G. A., Klure, L. J., Pond, E. C. \& GRANTHAM, G. L. (1982). Variability in growth of Phytophthora cinnamomi isolates in response to antibiotics. Phytopathology 72, 750-754.

Marchant, R. \& SMith, D. G. (1968). Effect of chloramphenicol on growth and mitochondrial structure of Pythium ultimum. Journal of General Microbiology 50, 391-397.

Matsumae, A. \& Cantino, E. C. (1971). Sensitivity of the spores of Blastocladiella emersonii and related fungi to antibiotics and some other drugs. Journal of Antibiotics 24, 77-84.

MCMEeKIN, D. (1973). Streptomycin inhibition of Peronospora parasitica and its host reversed by manganese and calcium. Phytopathology 63, 34-36.

Muller, K. O., Mackay, J. H. E. \& Friend, J. N. (1954). Effect of streptomycin on the host-pathogen relationship of a fungal phytopathogen. Nature, London 174, 878-879.

MULLER, W. H. (1958). The influence of antibiotics on microorganisms causing fruit and vegetable rots. American Journal of Botany 45, 183-190.

NewCOMER, E. H. (1953). A new cytological and histological fixing fluid. Science 118, 161.

OgaWA, J. M., McCaIN, A. H. \& HaLl, D. H. (1960). Streptomycin absorption in diseased and healthy hop tissues and its effect on the downy mildew organism and mildew development. Phytopathology 50, 278-280.

PestKA, S. (1975). Chloramphenicol. In Antibiotics III. Mechanism of Action of Antimicrobial and Antitumour Agents, pp. 310-395. Edited by J. W. Corcoran \& F. E. Hahn. Berlin \& New York: Springer Verlag.

ROOKE, D. M. (1983). Antibiotic sensitivity, resistance and dependence in Phytophthora infestans (Mont.) de Bary. Ph.D. thesis, University of Wales.

Rooke, D. M. \& Shattock, R. C. (1984). Cation antagonism of streptomycin action in a wild-type and dependent mutant of Phytophthora infestans. Transactions of the British Mycological Society (in the Press).

Shaila, M. S. \& Gopinath, K. P. (1974). Mechanism of streptomycin action. Journal of Scientific and Industrial Research 33, 467-474.

Shattock, R. C. \& Shaw, D. S. (1975). Mutants of Phytophthora infestans resistant to, and dependent upon antibiotics. Transactions of the British Mycological Society 64, 29-41.

SHAw, D. S. (1965). Drug resistance and morphological variation in Phytophthora cactorum. Ph.D. thesis, University of Glasgow, Scotland.

Shaw, D. S. \& Elliot, C. G. (1968). Streptomycin resistance and morphological variation in Phytophthora cactorum. Journal of General Microbiology 51, 75-84.

SHAw, D. S. \& KHAKI, I. A. (1971). Genetical evidence for diploidy in Phytophthora. Genetical Research 17, 165-167.

SwiEzYNSKI, K. M. \& JANKowsKa, H. (1970). Drug resistant isolates of Phytophthora infestans. Genetica polonica 11, 27-35.

UPPAL, B. N. (1926). Relation of oxygen to spore germination in some species of the Peronosporales. Phytopathology 16, 285-292.

VAARTAJA, O. (1960). Selectivity of fungicidal materials in agar cultures. Phytopathology 50, 870-873.

VöRös, J. (1963). Mode of action of selective fungistatic effects of streptomycin. Nature, London 199 , 1110-1111.

Vörös, J. (1965). Streptomycin sensitivity of Oomycetes due to increased absorption of streptomycin by their mycelia. Phytopathologische Zeitschrift 54, 249257. 